\title{
Para uma \\ Caracterização da Psicologia Social Brasileira
}

Characterization Of Brazilian Social Psychology

Para Una Caracterización De La Psicología Social Brasileña

Leonardo Pinto de Almeida

Universidade Federal Fluminense 
Resumo: O presente artigo tem como objetivo construir um esboço panorâmico da história da psicologia social brasileira. Inicialmente, partimos da intuição de Farr sobre a diferença conceitual entre psicologias sociais sociológicas e psicológicas para com isso estabelecer pontos de comparações entre as diversas perspectivas em Psicologia social. Analisamos diversos grupos teóricos para tentar construir um modo de compreensão sobre as implicações políticas, metodológicas e práticas de suas respectivas posições. Em nosso horizonte de reflexão, tomamos as psicologias sociais associadas ao behaviorismo, à Psicologia comparativa e ao cognitivismo, em solo norte-americano. Traçamos as influências da Psicologia cognitivista em solo brasileiro, mostrando que estava ligada à busca de variáveis dotadas de estabilidade, ao postulado da neutralidade do investigador e às noções de adaptabilidade e produtividade. Após a crise dessa perspectiva, observamos a influência da teoria das representações sociais e da teoria crítica em relação à Psicologia socio- histórica. Esta fundamenta uma ideia de homem associada ao materialismo dialético, à historicidade e à transformação social. Além da perspectiva socio-histórica, refletimos ainda sobre a Psicologia social relacionada ao problema das instituições para assim traçarmos as implicações críticas dessa perspectiva e da socio-histórica em relação ao pensamento norte-americano.

Palavras-chave: Psicologia social-História. Psicologia-Teoria. Teorias. Metodologia.

\begin{abstract}
This article aims to build a panoramic sketch of the history of Brazilian social psychology. Initially, we start from the intuition of Farr about the conceptual difference between psychological and social psychology to establish the comparisons between the various perspectives in social psychology. We analyzed various theoretical groups to try to build an understanding of the implications of policies, guidelines and practices in their respective positions. In our reflection, we take the social psychology associated with behaviorism, cognitivism and comparative psychology in the USA. We trace the influences of cognitivist psychology in Brazil, showing that it was linked to the pursuit of stability, neutrality of the investigator and the concepts of resiliency and productivity. After the crisis of that perspective, we see the influence of the theory of social representations and critical theory in relation to socio-historical psychology. The socio-historical psychology had an idea of man associated with dialectical materialism, historicity and social transformation. We also reflect on the social psychology related to the institutions' problems to think over the critical implications of this perspective and the socio-historical psychology in relation to the American thought.
\end{abstract}

Keywords: Social psychology-History. Psychology-Theory. Theories. Methodology.

Resumen: El presente artículo tiene como objetivo construir un esbozo panorámico de la historia de la psicología social brasileña. Inicialmente, partimos de la intuición de Farr sobre la diferencia conceptual entre psicologías sociales sociológicas y psicológicas para con eso establecer puntos de comparaciones entre las diversas perspectivas en Psicología social. Analizamos diversos grupos teóricos para intentar construir un modo de comprensión sobre las implicaciones políticas, metodológicas y prácticas de sus respectivas posiciones. En nuestro horizonte de reflexión, tomamos las psicologías sociales asociadas al behaviorismo, a la Psicología comparativa y al cognitivismo, en suelo norteamericano. Trazamos las influencias de la Psicología cognitivista en suelo brasileño, mostrando que estaba relacionada a la búsqueda de variables dotadas de estabilidad, al postulado de la neutralidad del investigador y a las nociones de adaptabilidad y productividad. Después la crisis de esa perspectiva, observamos la influencia de la teoría de las representaciones sociales y de la teoría crítica en relación a la Psicología socio-histórica. Ésta fundamenta una idea de hombre asociada al materialismo dialéctico, a la historicidad y a la transformación social. Además de la perspectiva sociohistórica, reflexionamos asimismo sobre la Psicología social relacionada al problema de las instituciones para que así tracemos las implicaciones críticas de esa perspectiva y de la socio-histórica en relación al pensamiento norte-americano.

Palabras clave: Psicología social-Historia. Psicología-Teoría. Teorías. Metodología.

A Psicologia social teve sua emergência em solo norte-americano no século XX. O behaviorismo tornou-se hegemônico por volta dos anos 30, e proporcionou o surgimento de uma compreensão individualizante do socius, por entender que a psicologia dos indivíduos serviria para compreender a sociedade.
A imigração dos pensadores gestaltistas, em decorrência da ascensão de Hitler, foi o estopim para o surgimento de uma psicologia social cognitivista que, como a behaviorista, mantinha uma postura individualizante, experimentalista e a-histórica, mantendo uma distinção entre indivíduo e sociedade. A 
Robert Farr (1998), em seu livro sobre as raízes da Psicologia social, aponta o embate entre as perspectivas psicológica e sociológica. Ele argumenta que a Psicologia social moderna floresceu em solo norteamericano no período posterior à Segunda Guerra Mundial, sendo que a perspectiva hegemônica passou a ser a psicológica devido à individualização do social, implementada tanto pelo behaviorismo (entre as duas guerras) quanto pelo cognitivismo no período que se sucedeu à Segunda Guerra Mundial.
Psicologia social passou a ser compreendida como o estudo das interações humanas e debruçou-se sobre os problemas relativos às atitudes e aos valores, que podiam ser negativos, como o preconceito, ou positivos, como a liderança. Outro foco bastante abordado pela psicologia social norteamericana foi o funcionamento do grupo como dispositivo de produtividade, seguindo as demandas do capitalismo avançado daquele país.

Essa teoria tornou-se hegemônica após a Segunda Guerra Mundial, devido aos planos de reestruturação das universidades europeias e japonesas e pelo amplo desenvolvimento das pesquisas nos Estados Unidos. No entanto, nos anos 70, essa hegemonia começou a ser abalada pelos questionamentos de psicólogos latinoamericanos, ao afirmarem que os modelos teóricos estadunidenses não condiziam com a realidade dos povos de seus países. No Brasil, tal abalo desencadeou uma crise de paradigmas que acabou por firmar na Psicologia social do País a perspectiva sociológica, que primava pelo compromisso com a população e com suas respectivas mazelas.

Como consequência, observamos hoje um quadro bastante influenciado pela teoria crítica, pela representação social e pelas teorias das instituições, que caracterizam algumas diferenças e semelhanças na área. Neste artigo, pretendemos traçar um panorama histórico da Psicologia social no Brasil a partir da ideia de Robert Farr sobre a existência de formas sociológicas e psicológicas em psicologia social, com o intuito de marcar as posições tomadas nessa disciplina em nosso país e assim melhor caracterizá-la em suas peculiaridades.

\section{Um esboço panorâmico}

Ao analisarmos a história da Psicologia social, observamos o embate entre perspectivas psicológicas e sociológicas ao longo de seu desenvolvimento. No presente texto, debruçar-nos-emos sobre alguns desses grupos teóricos, com o intuito de examinar suas implicações políticas, metodológicas e práticas, fundamentando nossa visão histórica.

Nessa fundamentação argumentativa, partiremos de caracterizações teóricas e metodológicas de acordo com o movimento histórico da Psicologia social, examinando as peculiaridades do behaviorismo, do cognitivismo, da Psicologia comparada, das representações sociais, da Psicologia sociohistórica e da Psicologia social ligada ao problema das instituições.

Robert Farr (1998), em seu livro sobre as raízes da Psicologia social, aponta o embate entre as perspectivas psicológica e sociológica. Ele argumenta que a Psicologia social moderna floresceu em solo norte-americano no período posterior à Segunda Guerra Mundial, sendo que a perspectiva hegemônica passou a ser a psicológica devido à individualização do social, implementada tanto pelo behaviorismo (entre as duas guerras) quanto pelo cognitivismo no período que se sucedeu à Segunda Guerra Mundial.

No entanto, antes da instalação da perspectiva individualista em solo norte-americano, vemos o surgimento de uma psicologia social comparativa, baseada em uma perspectiva evolucionista fundamentada no Handbook of Social Psychology, de Murchison, de 1935. Esse trabalho, segundo Farr (1998), revela uma perspectiva sociológica da Psicologia social por se fundamentar em uma analítica histórica dos fenômenos filogenéticos e na história social, em uma forma de considerar o social com metodologia multidisciplinar de análise dos fatos e fenômenos sociais.

Entretanto, podemos ver que, com o fortalecimento hegemônico do behaviorismo entre as duas guerras, essa perspectiva foi sobrepujada em solo norte-americano. A vitória do behaviorismo sobre a Psicologia 
1 Para melhor aprofundamento da ascensão do behaviorismo nos Estados Unidos, cf. Schultz e Schultz (2001).

2 As pesquisas ex post facto contam com pesquisas de levantamento e pesquisas de campo, observam um fenômeno já ocorrido para inferir suas causas e as pesquisas experimentais, divididas em experimento de campo e de laboratório, em que o pesquisador manipula previamente as variáveis a serem analisadas (Rodrigues, 1979). social comparativa se deu pelo declínio do evolucionismo e pela separação entre as disciplinas.

É interessante observarmos como a separação entre indivíduo e sociedade foi resolvida com uma ferramenta implementada pela psicologia social norte-americana: o conceito de grupo, entendido como elo intermediário entre os dois. Em Grupo: a Afirmação de um Simulacro (2007), Barros mostra que o trabalho de Mayo, em 1924, na Western Eletric Company, foi o estopim para o entendimento do grupo como dispositivo de melhor produtividade que terá seu avanço nas duas perspectivas psicológicas, fundadas em solo norte-americano.

A vitória do behaviorismo contra o funcionalismo e a Psicologia comparada ${ }^{1}$ marcou a derrota da perspectiva histórica na análise do comportamento, dando lugar a uma perspectiva a-histórica que se fundamentava na busca de leis que regem as interações sociais. A visão de que a pesquisa deveria servir para a depuração precisa das variáveis, pelo meio de pesquisas ex post facto e experimentais, ${ }^{2}$ foi tomando espaço até tornar-se hegemônica com o advento do cognitivismo.

Assim, F. H. Allport (1924), em seu livro Social Psychology, fundamenta a Psicologia social como ciência comportamental e experimental. Ele parte da ideia de que a Psicologia social não seria uma Geisteswissenschaft (ciência do espírito), como trataremos adiante em Wundt, mas uma Naturwissenschaft (ciência natural). Desse modo, para compreender a relação entre o indivíduo e a sociedade, a Psicologia social deveria se valer de formas analíticas provindas das ciências da natureza. É interessante observarmos com Foucault (1957/1999), em seu texto $A$ Psicologia de 1850 a 1950, que há, no início da Psicologia - assim como nos objetivos traçados pelos behavioristas e cognitivistas e também na Psicologia social -, uma vontade de verdade que busca as naturezas, as essências depuradas do homem por meio de experimentos que retiram a sua história. Será somente mais tarde, na história da Psicologia e da Psicologia social que a compreensão do homem como sujeito histórico irá tomar corpo em oposição a essa subjetividade naturalizada pelas psicologias que se declaram provindas das ciências naturais.

Se retornarmos um pouco mais na História, podemos observar esse dilema entre as formas psicológicas e sociológicas da Psicologia social, conforme os fundamentos teóricos levantados por Wundt no início da Psicologia.

Wundt formulou a base de duas perspectivas psicológicas, uma relacionada à Psicologia experimental e outra fundamentadora de uma psicologia dos povos. A primeira estaria associada ao que os alemães chamavam de Naturwissenschaft (ciência natural), e a segunda, à Geisteswissenschaft (ciência do espírito). Essa dicotomia fundamenta duas psicologias com objetos e métodos de análises diferentes. A Psicologia experimental se baseava na introspecção como método de análise usado no laboratório para analisar certos comportamentos do indivíduo e da dinâmica da consciência, enquanto a segunda se fundamentaria na análise de religiões, mitos e produtos culturais em geral. Wundt estabeleceu essa diferença por acreditar que os processos mais profundos do psiquismo e suas produções culturais decorrentes não poderiam ser analisados experimentalmente. Sobre esse fato, Schultz e Schultz afirmam o seguinte:

A Psicologia cultural tinha que ver com a investigação de vários estágios do desenvolvimento mental, manifestos na linguagem, na arte, nos mitos, nos costumes sociais, nas leis e na moral. As implicações dessa obra para a Psicologia têm um significado maior do que seu conteúdo; ela serviu para dividir a nova ciência em duas partes, a experimental e a social (Schultz \& Schultz, 2001, p. 80) 
Assim, Wundt utilizava o método experimental, pelo meio da interferência e da manipulação do pesquisador em relação ao objeto analisado, em sua psicologia experimental, fundando assim uma psicologia da experiência, enquanto usava o método de observação, fundado na apreensão dos fenômenos, por meio de investigações indiretas através de relatos e de estudos etnológicos, dentre outros.

Como indicado anteriormente, Wundt afirmou veementemente a impossibilidade de se estudar os processos psíquicos superiores por meio do experimento. No entanto, podemos ver, ao longo da história da Psicologia, críticas diretas a essa ideia, como nos trabalhos de Ebbinghaus sobre o estudo experimental da aprendizagem e da memória, e de Külpe sobre o pensamento sem imagens (Schultz \& Schultz, 2001).

As críticas da vertente positivista a essa recusa, da possibilidade de análise experimental de fenômenos psicológico-culturais, deu origem ao esquecimento, ou melhor, à obliteração do desenvolvimento de uma Volkërpsychologie (psicologia dos povos). Esse "repúdio positivista de Wundt", para usar a feliz expressão de Danziger, possibilitou o fortalecimento de uma perspectiva em Psicologia social, fundamentada no experimentalismo e no positivismo, apontando uma individualização do social, percebida em seu desenvolvimento posterior com o behaviorismo e com o cognitivismo (Farr, 1998).

O repúdio fundamentou em solo norteamericano a substituição do psiquismo pelo organismo como objeto e da transição da Filosofia, como disciplina-mãe, para a biologia. Esse movimento de recusa positivista da psicologia social de Wundt foi um passo importante para a Psicologia social se tornar, aos olhos norte-americanos, uma ciência natural, daí a afirmação de Robert Farr que o que era uma Geisteswissenschaft em Wundt se tornou uma Naturwissenschaft em Floyd Allport.

Assim, voltemos ao solo norte-americano, com o fortalecimento do behaviorismo e o desaparecimento, nas Américas, da Psicologia comparativa, no período entre as duas guerras. Em seu livro Social Psychology, Floyd Allport (1924) classifica a Psicologia social como ciência comportamental e experimental. Essa forma de ver a Psicologia social é uma forma psicológica, que individualizou e rebateu o aspecto social sobre a análise do comportamento. Outra perspectiva psicológica em Psicologia social surgida em solo norte-americano é a Psicologia social cognitiva, que, mesmo sendo diferente em sua base teórica em relação à anterior, tem algumas consequências políticas e metodológicas semelhantes em sua individualização do âmbito social.

Cartwright, em sua análise histórica da Psicologia social, sustenta a grande importância da figura de Hitler para o surgimento da Psicologia social moderna, fundamentada em solo norteamericano no período posterior à Segunda Guerra Mundial. Essa afirmação se sustenta na análise histórica das consequências das perseguições aos povos judeus, implementadas pelo ódio nazista. Devido a esse fato, muitos intelectuais europeus migraram para a América para fugir do ódio nazista. Dentre esses intelectuais, estavam os teóricos da Gestalt, como Kurt Lewin, Heider, Köhler, Koffka e Wertheimer, dentre outros.

A ascensão do nazismo na Alemanha, com seu anti-intelectualismo e seu anti-semitismo, resultou como se sabe na migração para América de vários professores, cientistas e artistas. Embora esse grande deslocamento de talentos intelectuais teve seus efeitos observados em todas as dimensões da ciência e da cultura, ele foi especialmente crítico para a Psicologia social. É difícil imaginar como o campo seria hoje se pessoas como Lewin, Heider, Köhler, Wertheimer, Katona, Lazarsfield e Brunswiks não tivessem vindo aos Estados Unidos, como o fizeram (Cartwright, 1979, p. 85) 
Dessa migração forçada, surgiu o confronto entre duas perspectivas psicológicas: o behaviorismo e o gestaltismo, o primeiro baseado no positivismo e na análise do comportamento, e o segundo fundado em uma perspectiva fenomenológica e no exame da percepção.

Segundo Farr (1998), muitos teóricos da Gestalt não haviam se defrontado com o behaviorismo antes, e foi justamente esse entrechoque de ideias que possibilitou o surgimento da psicologia social moderna, a cognitivista. No entanto, podemos observar que ambas as teorias (behaviorismo e gestaltismo) individualizaram o social, cada uma de seu jeito, e se constituíram como primeira rebatendo o aspecto social sobre o comportamento do indivíduo e o segundo, em termos de percepção. Ambas as formas psicológicas de Psicologia social norteamericana se definem como o estudo das interações sociais que procuram relacionar fatores ou variáveis dotadas de estabilidade, daí a afirmação de Aroldo Rodrigues de que a Psicologia social é uma ciência neutra, por buscar relações estáveis ${ }^{3}$ (Bock, Ferreira, Gonçalves, \& Furtado, 2007).

3 Em Silvia Lane e o Projeto do Compromisso Social da Psicologia, os autores contrapõem as ideias de Rodrigues de que a Psicologia social é uma ciência neutra, e as de Lane, ao afirmar que ela não é neutra, mas política.

4 Aqui, ressoa a afirmação de $\mathrm{F}$. H. Allport (1924) de que a psicologia do indivíduo explica a psicologia social.

5 Para uma explicitação das premissas de cada uma destas teorias, cf. Rodrigues (1979), Reich e Adcock (1976) e Krüger (1986).

A análise das interações sociais se baseia na tentativa de construção teórica de leis sobre o comportamento ou a percepção dos indivíduos na sociedade, apostando na ideia de que a psicologia do indivíduo explica a psicologia da sociedade. Poderíamos acrescentar à reflexão de Cartwright (1979) que não foi tão somente a imigração dos gestaltistas que aponta a marca das consequências da Segunda Guerra na psicologia social moderna, pois também muitos de seus objetos de análise decorrem de preocupações sublinhadas socialmente pela ascensão do nazismo, como o exame do papel da obediência à autoridade, do poder social, do conformismo e da agressão. No entanto, podemos assinalar que a análise formas psicológicas de Psicologia social, a

das atitudes se tornou um dos focos principais da psicologia social norte-americana (Reich \& Adcock, 1976; Rodrigues, 1979).

A psicologia social norte-americana, dentro desses moldes, revela uma forma psicológica de Psicologia social. Ela tem, segundo Helmut Krüger (1986), como principais aspectos: 1) o individualismo - preocupação em formular leis psicológicas relativas ao indivíduo em suas relações sociais $\left.{ }^{4}, 2\right)$ o experimentalismo, 3) a microteorização, 4) o etnocentrismo - generalização teórica de experimentos norte-americanos para a aplicação em outras culturas, 5) o cognitivismo - devido à prevalência dessa concepção em relação ao behaviorismo e à psicanálise e 6) o a-historicismo - devido à busca de formulação teórica de leis generalizáveis para o comportamento do indivíduo em sociedade, em que se essencializa o indivíduo e sua relação com a sociedade retirando seu componente histórico criador.

Dentre algumas das principais teorias formuladas pela Psicologia social norteamericana, estão: a dissonância cognitiva e a de comparação social de Festinger, o princípio do equilíbrio e a teoria da atribuição da causalidade de Heider, a teoria da direção à simetria de Newcomb e a teoria da reatância psicológica de Brehm, dentre outras ${ }^{5}$.
É interessante observarmos, com Barros, como a psicologia social norte-americana abandonou as noções europeias de massa e de coletivo para usar o grupo. Na Europa, vemos, no século XIX, uma postura reacionária das massas por ser supostamente descontrolada e irracional em Le Bon e uma visão libertária associada à revolução em Marx (Silva, 2005; Barros, 2007). A psicologia social norteamericana baseia suas análises em grupos ou microgrupos, como salienta Krüger (1986), com o intuito de melhor adaptar os indivíduos, visando também a um aumento de produtividade e, em consequência, de controle. Assım, adaptação e produtividade 
serão os principais objetivos dessa psicologia, que, de certa forma, naturaliza o social.

A metodologia dominante baseada no positivismo e utilizada por essa perspectiva é experimental, que se apoia em um controle e planejamento estatístico da pesquisa e na análise de hipóteses construídas. Ela era fundamentada ou em análises em laboratório ou em pesquisas de campo, e dava mais importância à primeira em muitos dos casos (Krüger, 1986).

A psicologia social norte-americana se tornou hegemônica depois da guerra, devido tanto à reconstrução das universidades europeias e japonesas no período pós-guerra quanto à colonização cultural das Américas nos anos que antecederam a crise da Psicologia social, nos anos 70 .

No entanto, antes de aportarmos na problemática latino-americana, faremos um breve adendo para apresentar uma perspectiva sociológica em Psicologia social apontada por Farr em seu livro, surgida no período do pós-guerra em solo europeu, a teoria das representações sociais, de Moscovici. Essa perspectiva mostra um movimento dialógico entre indivíduo e sociedade.

A teoria das representações sociais fundamenta a análise do conjunto de saberes que circulam hodiernamente em nossa sociedade, constituindo focos principais de construção social de identidades. Essa teoria será recuperada nos estudos latinoamericanos em Psicologia social em seu embate teórico contra as perspectivas psicológicas hegemônicas.

Diferentemente de Allport em sua análise positivista da história da Psicologia social que aponta Comte como antecessor, Moscovici sublinha Durkheim como antecessor da Psicologia social, com sua distinção entre representações coletivas e representações individuais. Essa distinção de Durkheim muito se assemelha à apontada por Wundt entre a Psicologia experimental e a social (Moscovici, 2003).

As representações individuais, segundo Durkheim, seriam o objeto da Psicologia, pois representaram as vicissitudes do indivíduo, enquanto as representações coletivas marcariam o objeto da Sociologia, sendo os produtos representacionais de uma dada cultura, como religião, mitos, representações simbólicas da sociedade.

As representações sociais se assemelham às representações coletivas, como formas representacionais de determinada cultura. No entanto, o caráter estático das representações coletivas é trocado por um caráter dinâmico e de transformação que fundamenta a nomeação conceitual diferenciada (Spink, 1993). Moscovici está interessado no dinamismo das representações em sua construção da sociedade contemporânea e das identidades fundadas nessas representações.

As representações sociais são mais dinâmicas que as representações coletivas. Sperber (citado por Alexandre, 2004), quando analisa essa distinção, apropria-se de uma metáfora médica, ao afirmar que as representações coletivas, devido ao seu caráter estático, se assemelham à endemia, já que as endemias são as doenças reinantes em um ambiente social, enquanto as representações sociais são dinâmicas como as epidemias, já que surgem tão rapidamente quanto desaparecem, assemelhando-se a modismos.

Quando Moscovici (2003) se pergunta como surgem as representações sociais, conclui que elas aparecem em um movimento de familiarização do desconhecido. Quando surge o novo, o estranho, o movimento recorrente dos homens é o de torná-lo familiar. É desse modo que as representações sociais surgem, através de um movimento dinâmico 
de familiarização do estranho em categorias e representações, que revelam dimensões afetivas e cognitivas. Para Moscovici, esse movimento surge cognitivamente através de dois processos: o de ancoragem e o de objetivação (Moscovici, 2003; Sá, 2002).

O processo de ancoragem se caracteriza pelo encaixe do desconhecido em categorias pré-existentes. "A ancoragem consiste na integração cognitiva do objeto representado a um sistema de pensamento social préexistente e nas transformações implicadas em tal processo" (Sá, 2002, p. 46), como no caso da AIDS, que, quando surgiu, como doença desconhecida, foi logo classificada de peste gay. A ancoragem é sinônimo de classificação e denominação. Ela está do lado da categorização do desconhecido que se torna familiar, enquanto a objetivação se fundamenta na construção de imagens naturalizadas que tomam o lugar do desconhecido e assim o explicam.

Essa teoria foi usada por muitos dos teóricos latino-americanos em sua luta por uma psicologia social comprometida com os problemas de seus respectivos países e em uma tentativa de possibilitar a conscientização dos povos, subjugado por forças ideológicas. Assim, seu uso buscava conscientizar os sujeitos que são acometidos por representações sociais a serviço de forças ideológicas hegemônicas.

Esse problema das relações sociais (RS) com a ideologia pode ser visto de duas formas: primeira, as RS e a ideologia diferem se pensarmos que as RS são dinâmicas, relacionadas com a transformação, e a ideologia é estática, e, segunda, e mais interessante, as RS e a ideologia se assemelham, pois ambas são formas simbólicas. No entanto, a ideologia se caracteriza por ser uma forma simbólica a serviço de relações de dominação, logo, nem toda RS é ideológica, mas devemos verificar se ela fundamenta ou não uma relação de dominação (Guareschi, 2004). Os psicólogos sociais latino-americanos se debruçaram, em muito dos casos, nas representações sociais com o intuito de apontar o seu caráter ideológico.

Relacionando essa questão ao ponto em nossa argumentação sobre as consequências do desenvolvimento da Psicologia social em solo latino-americano, vemos claramente, em nossa história, como é marcante a colonização cultural sofrida pelos povos de nosso continente, e, com a Psicologia social, não foi diferente, como podemos observar no artigo Sobre a Psicologia Social no Brasil, entre Memórias Históricas e Pessoais, de Celso Pereira de Sá (2007).

Vemos no Brasil um desenvolvimento de uma nova postura em relação à Psicologia social surgida com a crise que a perspectiva até então vigente sofreu nos anos 70. No entanto, podemos observar dois momentos especiais para a Psicologia social que antecedem o surgimento da ABRAPSO (Associação Brasileira de Psicologia Social), que fundamenta as premissas do surgimento da Psicologia socio-histórica: os cursos de Psicologia social ministrados e seus livros correspondentes na década de 30-40, de Ramos e Bricquet, que mostravam uma perspectiva sociológica inspirada na multidisciplinaridade, como o Handbook of Social Psychology, de Murchison (Bonfim, 2004).

Porém, no pós-guerra, principalmente, nas décadas de 60 e 70, há um fortalecimento da perspectiva psicológica em Psicologia social derivada do pensamento positivista norte-americano, devido à formação de psicólogos sociais brasileiros nos EUA e à explosão bibliográfica de traduções de autores consagrados dessa perspectiva, como Festinger e Heider, dentre outros, como salienta Sá (2007). 
No entanto, em plena ditadura no nosso país, críticas provindas da Inglaterra e da França instalam uma crise nesses modelos hegemônicos norte-americanos em Psicologia social, o que traz a perda do privilégio da teoria de Festinger (dissonância cognitiva) para o caráter falseador da distinção entre indivíduo e sociedade, para a característica essencializante, naturalizante e a-histórica, uma crise que se instaurou inicialmente nas discussões no Congresso Interamericano em Miami, no ano 1976.

No entanto, foi apenas no encontro no Peru, em 1979, que se apresentaram críticas mais precisas e propostas de reformulação paradigmática para a psicologia social latinoamericana. Uma das críticas mais ferozes à perspectiva norte-americana tem a ver com a neutralidade do pesquisador, a perda do humano em seu tratamento a-histórico, a falsa dicotomia entre indivíduo e sociedade, e, principalmente, com o fato de que esses modelos importados não condizem com nossa realidade (Lane, 1981, 1982).

Poderíamos parafrasear a reflexão de Cartwright sobre a importância de Hitler para o nascimento da psicologia social moderna e dizer que o surgimento da psicologia social latino-americana deve muito às figuras ditatoriais instaladas em suas fronteiras, já que tanto a repressão das ditaduras quanto a imposição da hegemonia norte-americana impuseram a valorização do indivíduo em relação ao social. O individualismo é importante para ambas, porque sustenta a despolitização do social, como afirma Bourdieu (1998) em Contrafogos. Repressão e individualismo fizeram surgir, em contrapartida, uma psicologia social comprometida com a realidade social de nosso continente em contraposição ao movimento de despolitização.

Essa psicologia social, que é uma forma sociológica, teve como influências marcantes a teoria das representações sociais, a teoria crítica e a práxis marxista. No Brasil, temos Silvia Lane como uma de suas figuras fundamentais.

Enquanto a Psicologia social cognitiva se baseava em uma perspectiva naturalizante e dicotômica, valendo-se do método experimental e da neutralidade do investigador em suas análises das relações interpessoais e dos fatores sociais no indivíduo, a psicologia social brasileira (socio-histórica) se fundamentava no método do materialismo dialético, visando ao compromisso social.

Em Método Histórico Social na Psicologia Social (2005), diversos autores fundamentam as premissas teóricas e metodológicas dessa teoria, que foi chamada comumente de Psicologia sócio-histórica, em contraposição à psicologia social psicológica norte-americana. Eles afirmam que o materialismo positivista da psicologia social norte-americana se fundava na neutralidade, em um entendimento de que a psicologia do indivíduo explicaria a psicologia da sociedade, e que sua característica naturalizante se baseava na compreensão de uma cognição abstrata e descontextualizada e, por consequência, a-histórica. O materialismo histórico-dialético usado pelos psicólogos sócio-históricos, por outro lado, produzia uma visão comprometida com a realidade da população, já que defendiam o resgate da historicidade e a produção de conhecimento comprometido com a transformação social.

Como podemos observar, a Psicologia sociohistórica apostou principalmente no caráter histórico das relações sociais. Seu foco de análise recai sobre as realidades concretas do homem brasileiro e se vale da conceitualização da ideologia como fundamentadora das relações de dominação e da possível conscientização, mediante trabalhos em grupos, para permitir que os homens se desvencilhem dos poderes hegemônicos. 
É curioso observarmos a importância de dois conceitos usados por esses autores: o conceito de relação e da linguagem como mediador simbólico das relações humanas. Em Psicologia Social Crítica, Guareschi (2004) sustenta que o conceito-chave da Psicologia social seria o conceito de relação. Essa afirmação revela uma contraposição à psicologia social norte-americana, que busca valores universais que regiriam as interações humanas. Os valores universais estão do lado das naturalizações que sustentam certas relações de poder. O conceito de relação se opõe às ideias de natureza humana, pois, para um pensamento histórico, as essências são construções representativas precárias fundadas pelo medo da transformação.

Assim, Guareschi une os conceitos de relação, de história e de crítica para se contrapor às naturezas impostas pelas relações de dominação, fundadas nas diversas ideologias que circundam a sociedade. O homem é histórico e suas relações o constroem. Ele é produto e produtor da História. No entanto, sem o pensamento crítico, ele deixa de lado sua potencialidade de criador de sua própria história e reproduz as palavras hegemônicas regidas pelas ideologias dominantes.

Lane mostra bem que a relação estabelecida entre o homem e o mundo se dá pela mediação simbólica da linguagem. A palavra é um instrumento de comunicação entre os homens. No entanto, quando a palavra tem um significado congelado, único e naturalizado, ela se torna uma arma de poder, associada a formas de dominação.

Quando o nosso pensamento não confrontar as nossas ações e experiências com o nosso falar, (...) estaremos apenas reproduzindo as relações sociais necessárias para a manutenção das relações de produção da vida material em nossa sociedade (Lane, 1981, p. 37)

Como podemos ver, a Psicologia sóciohistórica se fundamenta na ideia do homem como ser histórico e na possibilidade de transformação social. A compreensão da ideologia como dominação aponta o entendimento de uma psicologia social crítica que tende ao compromisso social e à conscientização. Assim, sua maior preocupação não está em formular leis gerais sobre o comportamento social, mas sim, no entendimento das relações de dominação ideológicas e de sua possível saída, através da conscientização.

A metodologia dessa forma sociológica de Psicologia social critica veementemente a neutralidade da psicologia social norteamericana e aposta no trabalho com grupos através de métodos como a pesquisa-ação e a pesquisa-participação. ${ }^{6}$

Essas duas formas de pesquisa se assemelham pela participação do investigador em pesquisa, sendo que à pesquisa-ação se acrescentaria o caráter participativo, o interesse na transformação social do grupo, pela conscientização. Aqui podemos observar que, enquanto a psicologia social norteamericana usava o grupo como dispositivo de adaptação e de produtividade, a Psicologia soció-histórica o toma como dispositivo de conscientização.

Assim, poderíamos exemplificar com a diferença no trato da comunidade em duas formas teóricas distintas: na perspectiva norte-americana, o trabalho do psicólogo comunitário visa ao assistencialismo, e, no trabalho comunitário sob a perspectiva socióhistórica, visar-se-ia à autonomia do grupo, sendo este a base do compromisso social de transformação (Campos, 1998).

É interessante observar que a teoria das representações sociais é usada pelos psicólogos sociais brasileiros com o intuito de traçar panoramas da realidade brasileira. O grau de comprometimento com a transformação social também permanece como uma de suas premissas nos estudos da vida cotidiana, 
Em Nietzsche, la Généalogie, I'Histoire (1994) e A Verdade e Formas Jurídicas (1996), Foucault ressalta que sua preocupação está ligada a um questionamento da verdade, entendendo que as verdades são invenções fundadas por relações de força no seio da História. como nos trabalhos desenvolvidos em Textos em Representações Sociais (1999) e O Conhecimento do Cotidiano (2006). Alguns dos autores desses livros unem a perspectiva soció-histórica à teoria das RS. No entanto, gostaríamos de frisar que um dos objetivos do presente artigo é a construção do entendimento da psicologia social brasileira que possibilite apontar as diferenças e as semelhanças entre essas duas formas teóricas.

Podemos ainda indicar mais uma teoria de Psicologia social sociológica que é muito exercida em nosso país: a psicologia que gira em torno de questões relativas às instituições e ao poder, baseadas nas obras de Foucault, Deleuze, Guattari, e de autores da análise institucional que se debruçam sobre o recrudescimento da verdade instaurada em nossas instituições.

Em Instintos e Instituições, Deleuze afirma que os homens diferem dos animais por não haver um padrão para o seu comportamento, como no caso dos animais, mas sublinha que, no lugar do padrão instintivo, inventam as instituições que intermedeiam as relações entre os homens.

Qual é o sentido do social com relação às tendências? Integrar as circunstâncias em um sistema de antecipação, e integrar os fatores internos em um sistema que regra sua aparição, substituindo a espécie. É bem esse o caso da instituição. (...) Toda instituição impõe ao nosso corpo, mesmo em suas estruturas involuntárias, uma série de modelos, e dá à nossa inteligência um saber, uma possibilidade de prever e de projetar (Deleuze, 2006, p. 31)

Então, instituições intermedeiam as relações humanas. Dessa maneira ampla de ver as instituições, poderíamos dizer que, quando bebo cerveja com os amigos, a cerveja, o bar, as cadeiras, a mesa disponibilizam instituições que intermedeiam nossas relações, e a mesma coisa acontece quando leciono: a sala, o título de professor, a disposição dos alunos em suas cadeiras institucionalizam as relações estabelecidas nesse espaço.
Dentre os teóricos que se debruçam sobre as relações de poder e as instituições, as definições não são de todo homogêneas. Mas podemos notar que o grande problema para essas teorias está relacionado ao recrudescimento das verdades e às naturalizações dos comportamentos apresentadas no seio tanto dessas instituições que intermedeiam nossas relações quanto às instituições que governam nossos comportamentos através de diretrizes estatais, como as prisões e os hospitais psiquiátricos.

Em Nietzsche, la Généalogie, I'Histoire (1994) e A Verdade e Formas Jurídicas (1996), Foucault ressalta que sua preocupação está ligada a um questionamento da verdade, entendendo que as verdades são invenções fundadas por relações de força no seio da História.

Paul Veyne, em seu livro sobre Foucault, assinala o caráter revolucionário do método genealógico, por ele se fundar na ideia de que não há objeto natural. Sua crítica às noções de essência e de origem suscita o entendimento de que as práticas, surgidas em um determinado tempo histórico, causam o aparecimento dos objetos, e não o contrário. Assim, ele compreende que toda verdade é fabricada em um determinado tecido socióhistórico, inserindo o problema da verdade no tempo.

Foucault pensa que não existem verdades gerais, trans-históricas, porque os fatos humanos, atos ou palavras, não provêm de uma natureza, de uma razão que seria sua origem, nem refletem o objeto ao qual eles remetem (Veyne, 2008, p. 22)

Utilizando esse método, Foucault produz uma reflexão que indaga por uma história das verdades. Em História da Sexualidade 2 (1985), mostra como, através da união dos métodos arqueológico e genealógico, ele questionou, ao longo de sua obra, as práticas médicas, sociais, discursivas, epistêmicas, 
punitivas e de si, sempre permeando a problematização das verdades instituídas pela dinâmica do poder.

Através de sua pesquisa, Foucault pensou sobre as relações entre as instituições e os modos de existência produzidos por elas, indagando sobre as cronificações interpretativas que produziram a verdade sobre o louco, o criminoso, a ciência, a crítica e seus modos de existir correlatos. Essas cronificações são verdades que impõem regras de condutas comportamentais, mentais, institucionais e sociais.

O problema do poder e das instituições se instaura no congelamento do potencial criativo da palavra. Onde há congelamento da palavra, há recrudescimento de verdades e reificação de comportamento. No entanto, diferentemente da perspectiva socióhistórica, o problema do poder não é ideológico, pois o poder é visto aqui como multifacetado e positivado. Ele está em toda parte e em todas as relações. Ele não é negativo em si. A negatividade do poder se instaura na relação recrudescida. Aqui, o problema não é a ideologia que domina e oblitera a visão dos homens, e sim, algo ao mesmo tempo mais abrangente e mais sutil, a verdade (Foucault, 1995).

Assim, metodologicamente, essa busca do questionamento das verdades instauradas nas instituições se valerá da pesquisa-ação, mas também apontará a importância das análises das implicações do investigador com seu saber, com a instituição e com o grupo analisado (Kamkhagi \& Saidon, 2002). Desse modo, essa perspectiva sociológica da Psicologia social critica veementemente também a noção da neutralidade. Como vimos, a psicologia social norte-americana, apostando na neutralidade do investigador, sustenta a construção teórica de leis que explicam as interações sociais fundamentando-se no indivíduo.
E observamos também que as formas sociológicas em Psicologia social na teoria das RS, na Psicologia soció-histórica e na psicologia social das instituições incluem uma crítica à forma psicológica da psicologia social norte-americana. Ambas apostam na análise dos grupos como possibilidade de compreensão da dinâmica das relações sociais, sendo que as RS se debruçam no conjunto de saberes que constituem e constroem as identidades dos sujeitos e dos grupos. A Psicologia soció-histórica aposta na historicidade, no compromisso social de transformação da realidade, fundamentando uma crítica das relações ideológicas (de dominação) que sublinha a importância da conscientização dos sujeitos e dos grupos. Já a terceira entende a dinâmica do poder relacionado a um funcionamento microfísico do poder nas instituições e em suas relações. Ela tem como objetivo a circulação de palavras para quebrar o congelamento das vias de expressão instauradas nas relações estabelecidas nas instituições analisadas.

Por caracterizarem-se pela análise das relações, e não por uma busca de essências e de leis encontradas nas perspectivas psicológicas, as psicologias sociais sociológicas brasileiras, aqui analisadas, revelam um comprometimento político, cada uma à sua maneira, tendo como foco de semelhança a crítica ao positivismo, à assepsia experimental, à a-historicidade e à neutralidade do investigador. 
Leonardo Pinto de Almeida

Pós-doutorado em Psicologia pela Pontifícia Universidade Católica do Rio de Janeiro. Professor Adjunto da Universidade Federal Fluminense, Rio de Janeiro - RJ - Brasil.

E-mail: leonardo_almeida@id.uff.br

Endereço para envio de correspondência:

Rua Oswaldo Cruz, 28/701, Icaraí, Niterói, Rio de Janeiro, RJ - Brasil. CEP: 24230-210 


\section{Referências}

Abrantes, A. A., Silva, N. R. da, \& Martins, S. T. F.(2005). Método histórico-social na psicologia social. Rio de Janeiro: Vozes.

Alexandre, M. (2004). Representação social, uma genealogia do conceito. Revista Comum, 10(23), 122-138.

Allport, F. H. (1924). Social psychology. Boston: HoughtonMifflin.

Barros, R. D. B. (2007). Grupo: a afirmação de um simulacro. Porto Alegre: UFRGS Editora.

Bock, A. M. B., Ferreira, M. R., Gonçalves, M. G., \& Furtado, O. (2007). Sílvia Lane e o projeto do "Compromisso Social da Psicologia". Psicol. Soc. (online), 19(Esp. 2), 46-56.

Bonfim, E. M. (2004). Históricos cursos de psicologia social no Brasil. Psic. Soc. 16(2), 32-36.

Bourdieu, P. (1998). Contrafogos. Rio de Janeiro: JZE.

Campos, R. H. F. (Org.). (1998). Psicologia social comunitária: da solidariedade à autonomia. Petrópolis, RJ: Vozes.

Cartwright, D. (1979). Contemporary social psychology in historical social. Psychology Quarterly, 42(1), 82-93.

Deleuze, G. (2006). Instintos e instituições. In G. Deleuze, A ilha deserta e outros textos (pp. 29-32). São Paulo: lluminuras.

Farr, R. M. (1998). As raízes da psicologia social moderna. Petrópolis, RJ: Vozes.

Foucault, M. (1985). História da sexualidade 2, o uso dos prazeres. Rio de Janeiro: Graal.

Foucault, M. (1994). Nietzsche, la généalogie, l'histoire. In M. Foucault, Dits et écrits II (1970-1975) (pp. 136-156). Paris: Ed. Gallimard.

Foucaul, M. (1995). Verdade e poder. In M. Foucault, Microfísica do poder (pp. 1- 14). Rio de Janeiro: Graal.

Foucault, M. (1996). A verdade e as formas jurídicas. Rio de Janeiro: PUC-Rio, Nau Ed.

Foucault M. (1999). A psicologia de 1850 a 1950. In M. Foucault. Ditos e Escritos I (pp. 122-139). Rio de Janeiro: Forense Universitária. (Trabalho original publicado em1957).

Guareschi, P. A. (2004). Psicologia social crítica como prática de libertação. Porto Alegre: EDIPUCRS.

Guareschi, P. A., \& Campos R. H. F. (Orgs.). (2000). Paradigmas em psicologia social: a perspectiva latinoamericana. Petrópolis, RJ: Vozes.
Guareschi, P. A. \& Jovchelovitch, S. (Orgs.), (1999). Textos em representação social. Petrópolis, RJ: Vozes.

Heider, F. (1970). Psicologia das relações interpessoais. São Paulo: Ed. Pioneira.

Jacques, M. G. C. , Fonseca, T. M. G., Bernarde, N. M. G., Sérgio, A. C., Guareschi, P. A., \& Strey, M. N. (Orgs.). (2002). Psicologia social contemporânea, livro-texto. Rio de Janeiro: Vozes.

Kamkhagi, V. R. \& Saidon, O. (Orgs.). (2002). Análise institucional no Brasil. Rio de Janeiro: Editora Rosa dos Ventos.

Krüger, H. (1986). Introdução à psicologia social. São Paulo: E.P.U.

Lane, S. T. M. (1981). O que é a psicologia social. São Paulo: Brasiliense.

Lane, S. T. M. (1982). Psicologia social: o homem em movimento. São Paulo: Brasiliense.

Lane, S. T. M. (1985). Novas veredas da psicologia social. São Paulo: Brasiliense Educ.

Moscovici, S. (2003). As representações sociais. Petrópolis, RJ: Vozes.

Reich, B., \& Adcock, C. (1976). Valores, atitudes e mudança de comportamento. Rio de Janeiro: Zahar Ed.

Rodrigues, A. (1979). Psicologia social. Rio de Janeiro: Vozes.

Sá, C. P. (2002). O núcleo central das representações sociais. Rio de Janeiro: Vozes.

Sá, C. P. (2007). Sobre a psicologia social no Brasil, entre memórias históricas e pessoais. Psicologia e Sociedade, 19(3), 7-13.

Schultz, D., \& Schultz, S. E. (2001). História da psicologia moderna. São Paulo: Cultrix.

Silva, R. N. (2005). A invenção da psicologia social. Rio de Janeiro: Vozes.

Spink, M. J. P. (1993). O conceito de representação social na abordagem psicossocial. Cad. Saúde Públ., 9(3), 300-308.

Spink, M. J. P. (Org.). (2006). O conhecimento do cotidiano. São Paulo: Brasiliense.

Veyne, P. (2008). Foucault, sa pensée, sa personne. França: Albin Michel. 